\title{
The 12th Workshop on Antarctic Meteorology and Climate
}

\author{
Matthew A. LAZZARA ${ }^{* 1,2}$, Jordan G. POWERS ${ }^{3}$, Carol A. COSTANZA², David H. BROMWICH ${ }^{4}$, \\ Scott CARPENTIER ${ }^{5}$, and Steve R. COLWELL ${ }^{6}$ \\ ${ }^{1}$ Department of Physical Sciences, School of Arts and Sciences, Madison Area Technical College, Madison, WI 53704, USA \\ ${ }^{2}$ Antarctic Meteorological Research Center, Space Science and Engineering Center, University of Wisconsin-Madison, \\ Madison, WI 53706, USA \\ ${ }^{3}$ National Center for Atmospheric Research, Boulder, CO 80300, USA \\ ${ }^{4}$ Polar Meteorology Group, Byrd Polar \& Climate Research Center, The Ohio State University, Columbus, OH 43210, USA \\ ${ }^{5}$ Bureau of Meteorology, Hobart, Tasmania 7000, Australia \\ ${ }^{6}$ British Antarctic Survey, Cambridge CB3 0ET, United Kingdom
}

(Received 14 March 2018; revised 30 March 2018; accepted 2 April 2018)

Citation: Lazzara M. A., J. G. Powers, C. A. Costanza, D. H. Bromwich, S. Carpentier, and S. R. Colwell, 2018: The 12th Workshop on Antarctic Meteorology and Climate. Adv. Atmos. Sci., 35(7), 753-756, https://doi.org/10.1007/s00376-0188061-2.

\section{Overview}

The 12th Workshop on Antarctic Meteorology and Climate (WAMC), formerly known as the Antarctic Meteorological Observation, Modeling, and Forecasting (AMOMF) Workshop (AMOMFW), was held at the National Center for Atmospheric Research (NCAR) in Boulder, Colorado, USA on 26-28 June 2017. The annual workshop dates from 2006, and recent meetings have been the 10th AMOMF Workshop held in 2015 in Cambridge, United Kingdom (Colwell et al., 2016) and the 11th AMOMF Workshop held at the Byrd Polar \& Climate Research Center at The Ohio State University in 2016. This year, NCAR's Mesoscale and Microscale Meteorology (MMM) Laboratory hosted the event. The 12th WAMC was followed by two other meetings related to Southern Hemisphere science: one covering the plans for the Year of Polar Prediction-Southern Hemisphere (YOPP-SH) effort and the other covering the activities of the Southern Ocean Regional Panel (SORP). The WAMC objective is to bring the Antarctic meteorological and climate communities together to share developments, discuss results and issues, and consider collaborative plans. The workshop reviewed current and future Antarctic observation efforts, numerical modeling and forecasting, and a spectrum of polar scientific studies, with an emphasis on atmospheric research. The workshop had approximately 60 attendees from over 10 countries (Fig. 1).

\section{Observing Systems and Studies}

Presentations on Antarctic meteorological observing systems and efforts kicked off the workshop. The University of Wisconsin-Madison (UW-Madison) Automatic Weather Station (AWS) program field activities from the 2016-2017 season were reviewed (Fig. 2), with a short season being noted due to limited logistical support available. UW-Madison personnel outlined issues with UHF Communications in the Wisconsin AWS network near McMurdo Station, along with the likelihood that Pegasus North AWS will be replaced by a new AWS at Phoenix Air Field, after a 1-2 year "sideby-side" observing test period. The community also learned of a Major Research Instrumentation (MRI) project that has started at Madison College in partnership with UW-Madison to develop a next-generation electronics core for a new polar AWS. The British Antarctic Survey (BAS) reported on their program activities from the 2016-2017 season, also the move of Halley station where the main station was moved $23 \mathrm{~km}$ and their plans for winter automation going into the future. They also reported about the Halloween crack in the Brunt Ice Shelf that has forced Halley station to be closed for the 2017 winter season. The Korean Polar Research Institute (KOPRI) reviewed South Korea's staffed-station meteorological efforts and planned AWS deployments, as well as plans to move its observations to BUFR format for distribution to the Global Telecommunications System (GTS). Additionally, the observations will be relayed from King Sejong Station via the Korean Meteorological Administration to the GTS instead of being routed through Chile's Eduardo Frei station. Lastly, KOPRI informed the workshop of the variety of meteorological capabilities of the King Sejong and Jang Bogo

\footnotetext{
* Corresponding author: Matthew A. LAZZARA

E-mail: mlazzara@madisoncollege.edu
} 


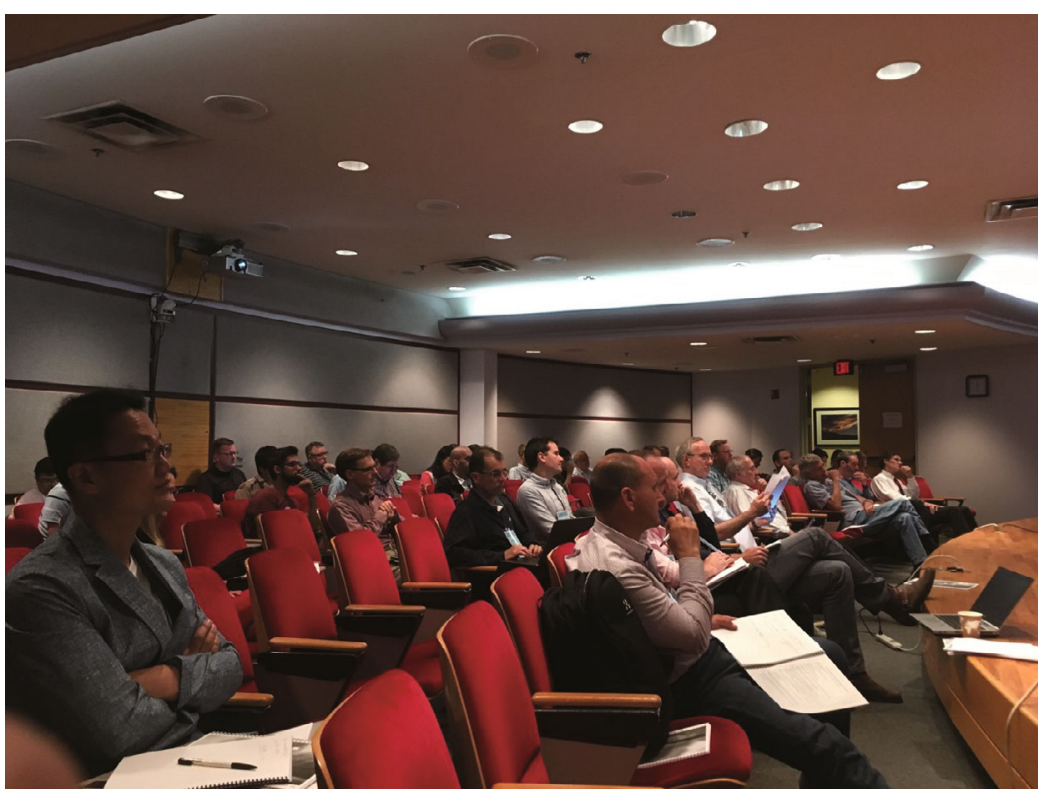

Fig. 1. Attendees at the WAMC workshop attentively listening to presentations.

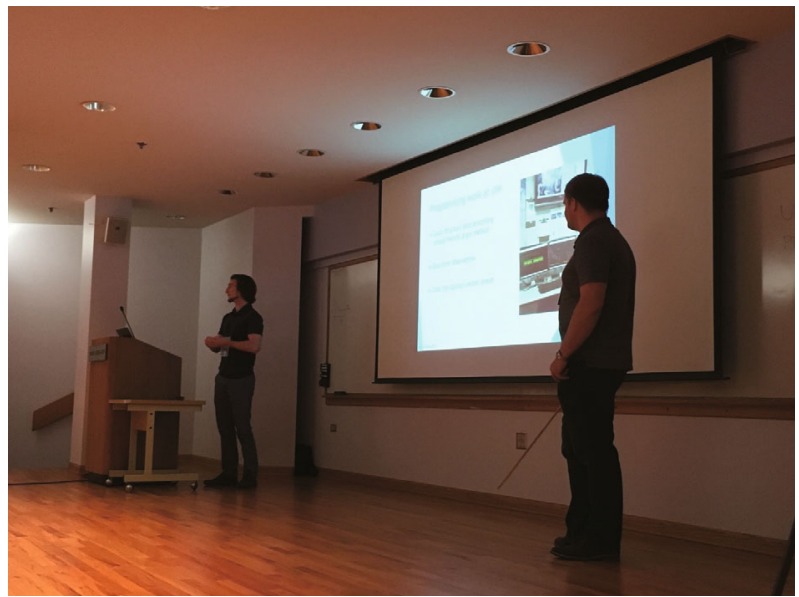

Fig. 2. Dave MIKOLAJCZYK (left) and Lee WELHOUSE (right) jointly present the challenges with the UHF transmissions with the UW-Madison AWS network.

stations, including launching radiosondes and observing via a 30-meter, 5-level instrumented tower recently installed at Jang Bogo station. A new precipitation study starting in the 2017-2018 field season in the Ross Island area was announced. The project will include several sites that will be instrumented in the McMurdo area, co-located at nearby AWS sites, to measure precipitation via various methods.

\section{Numerical Modeling Systems and Studies}

The workshop covered numerical modeling and forecasting systems for the Antarctic and studies using them. Reviews addressed the performance of the Australian Bureau of Meteorology's operational model and the United States' Antarctic Mesoscale Prediction System (AMPS). Regarding AMPS, one issue of the past year was a surface pressure bias found in the model used in AMPS WRF (the Weather Research and Forecasting Model), and was connected to missing observational data. A concerted effort to include observational data from a host of sources including GTS, AMRC, and BAS solved this problem. New computing available for AMPS on the National Center for Atmospheric Research's community platform "Cheyenne" will enable increased model resolution and an expanded forecast ensemble. Lastly, an assessment of the Model for Prediction Across Scales (MPAS) being run in the AMPS environment found MPAS's performance relative to WRF has improved over the year, although overall WRF retains a statistical edge. A presentation on the use of WRF-Ice in surface mass balance modeling across the Antarctic Peninsula was given where the model includes snow, ice, blowing snow, snow surface albedo 
as well as firn percolation processes. A presentation on the analysis of the regional climate model CCLM (COSMO-CLM) in the Weddell Sea region identified boundary layer problems, and was used to look at climate change in Antarctica as seen via a high-resolution regional climate model. A final presentation outlined the issues of downscaling high regional resolution global climate models and the bias these GCMs can create.

\section{Research Investigations}

The WAMC provides an opportunity for the Antarctic community to hear the latest results from a range of polar meteorological and climatic studies. This year, investigation topics included: atmospheric rivers impacting Antarctica; analyses of regional climate models and GCM ensembles; Antarctic weather and climate events (e.g., the 2016 west Antarctic melt event and the 2015 extreme temperature event in the Antarctic Peninsula); and tropical influences on the Antarctic atmosphere. On the operational side, there were presentations on the development of fog forecasting tools, meteorological support for base air operations, and analysis of a fog event by the American, Argentinian, and Australian forecasting groups respectively. Finally, there was an analysis done to help explain a new approach for analyzing the near-surface air temperature by calculating the freezing period at King George Island.

\section{Measurement and Observation Applications}

There were a number of reports on observational-based studies. These included: a project studying thin clouds at South Pole and their infrared radiative impact; the development of an improved ice water content and cloud particle morphology from cloud particle imagery collected in the Southern Ocean; observations of snowfall in the sea ice zone from the Antarctic Circumnavigation Expedition; an overview of the GABLS4 Model inter-comparison; and a project examining long-term temperature trends across Antarctica. In addition, the community was briefed on the Atmospheric Radiation Measurement (ARM) West Antarctic Radiation Experiment (AWARE) which has taken measurements to investigate Antarctic clouds and their radiative impact. Its data are now publicly available and have already been used in an investigation of a 2016 melt event presented at the workshop.

A special session was held on the outlook for the management of American Antarctic meteorological observation efforts and, specifically, for support of the United States meteorological data archive and distribution and the generation of satellite composite imagery. Central support for this cyberinfrastructure effort is no longer funded by National Science Foundation (NSF) as a science project. This tasking, which has been spearheaded by the Antarctic Meteorological Research Center (AMRC) at UW-Madison, is currently looking at either splintered and limited funding from non-NSF sources or no funding at all in the coming year. The community was informed of this and engaged in discussion on the perceived impacts and possible strategies, such as on what should be archived and what the future role of AMRC should be.

\section{Year of Polar Prediction-Southern Hemisphere (YOPP-SH) Meeting}

During the main workshop, Kirstin Werner of the YOPP program office presented an overview of the YOPP-SH effort. Following the workshop, YOPP-SH had its own meeting. Topics ranged from components of the YOPP program to active and planned field experiments such as MARCUS (Measurement of Aerosols, Radiation, and Clouds over the Southern Ocean) and SOCRATES (Southern Ocean Clouds, Radiation, Aerosol Transport Experimental Study).

The participants were informed that the YOPP project office now has a YouTube video channel. In addition, the YOPP has an endorsement process for proposed projects and experiments, and this and the list of sanctioned efforts were reviewed. As of the Summer of 2017, a new category of endorsement-institution endorsement-has been announced. This category is intended for institutions that have many projects that are contributing to the goals of YOPP, and its creation is expected to reduce the paperwork required for YOPP project endorsement. The YOPP data explorer will be a metadata clearing house for all YOPP projects that offer datasets associated with the project. There will be no actual data holdings in this clearing house, and other existing repositories are encouraged for the archival of any datasets generated during the campaign. One existing system is Pangea http://www.pangea.de, which is a recommended repository for YOPP investigators to place their datasets (König-Langlo, 2013).

At the meeting, each national contribution to YOPP-SH was reviewed. While some projects are funded and will definitely be a part of YOPP-SH, many investigations are waiting for funding or are at present undefined. Enhanced atmospheric observation for the core period of YOPP-SH is a central theme across all national efforts. Some countries will deploy extra AWSs (e.g., China), while others will increase the number of radiosonde launches (e.g., South Korea, Chile).

\section{Southern Ocean Research Panel (SORP)}

The week concluded with a meeting of the Southern Ocean Research Panel (SORP). The topics included the role and activities of several initiatives, including the Southern Ocean Observing System. Numerical modeling efforts, especially those 
involving coupled systems, were an emphasis. Other areas outlined some targeted improvements such as in Southern Ocean and adjacent areas data management efforts. The new effort of the Southern Ice Prediction Network (SIPN) has debuted, providing the first set of forecasts for Southern Ocean sea ice extent. David Bromwich gave a presentation that outlined the problems found in the variety of numerical model reanalysis efforts over the Antarctic and Southern Ocean. Another signature presentation was given by Sharon Stammerjohn, on the Polynyas, Ice Production and Seasonal Evolution in The Ross Sea (PIPERS) cruise from which she had just returned. PIPERS' main objective is to study air-sea-ice interactions during the austral autumn and into winter-spring time in the Ross Sea. The focus of the project is on observations of the atmospheric and oceanic heat balance along with accompanying sea ice changes_-both growth and evolution.

\section{Student Engagement}

With support from International Association of Meteorology and Atmospheric Sciences (IAMAS) via the International Commission on Polar Meteorology (ICPM), the Scientific Committee on Antarctic Research (SCAR), and the World Meteorological Organization (WMO), funding was available for graduate students and young scientists to attend the WAMC. Nine graduate students and young scientists were selected from a large applicant pool for complete or partial travel support. With encouragement for applicants across the international community, this support provided access to the workshop for those who would otherwise not be able to attend.

\section{Summary and Recommendations}

The WAMC provides an excellent forum for the Antarctic meteorological and related communities to discuss scientific and logistical issues. While the purposes of the meeting are to exchange information, and facilitate collaboration and coordination, a few recommendations emerged.

- Increased and coordinated atmospheric and oceanic observing during YOPP-SH is desired.

- During the YOPP-SH special observing period (mid-November 2018 through mid-February 2019), the workshop advocates injection into the GTS of as many of the special observations as possible so the data can be utilized by the community in real time. This is especially for the benefit of numerical weather prediction efforts (e.g., centers such as the National Centers for Environmental Prediction (NCEP) and the European Centre for Medium-Range Weather Forecasts (ECMWF)).

- Maintenance of a community archive/data center focused specifically on Antarctic meteorological data, such as AMRC over the years, is important. The concept has strong community support, but a clear understanding and exposition of why to archive such data in this setting is necessary. This has now been formulated and is available online: http://amrc.ssec.wisc.edu/CyberinfrastructureReport_August01_2017.pdf

All of the presentations from the workshop as well as extended abstracts are available from the 12th WAMC web site, https://www.mmm.ucar.edu/workshop-antarctic-meteorology-climateyopp-sh-meetingsorp-meeting. The 13th WAMC (2018) is scheduled for 16-19 July 2018 and will be hosted by UW-Madison and Madison College in Madison, Wisconsin, USA http://amrc.ssec.wisc.edu/meetings/meeting 2018.html. Themes for the workshop will continue to be centered around Antarctic observations, numerical modeling, weather forecasting, and atmospheric research. Topics associated with YOPP-SH will also be included.

Acknowledgements. The authors wish to thank IAMAS/ ICPM, SCAR and WMO for their travel support of graduate students and young scientists' participation in this workshop. Support from the Office of Polar Programs, Geoscience Directorate, National Science Foundation via grants \#PLR-1625904, \#PLR-1543305, and \#PLR-1535632 is appreciated. The authors also wish to thank the National Center for Atmospheric Research and its Mesoscale and Microscale Meteorology Laboratory for hosting the workshop and providing support for it.

\section{REFERENCES}

Colwell, S. R., A. M. Cayette, M. A. Lazzara, J. G. Powers, D. H. Bromwich, J. J. Cassano, and S. Carpentier, 2016: The 10th Antarctic Meteorological Observation, Modeling, and Forecasting Workshop. Adv. Atmos. Sci., 33(5), 656-658, https://doi.org/10.1007/s00376-016-6012-3.

König-Langlo, Gert, 2013: Basic and other measurements of radiation at Neumayer Station in 2012, links to datasets. Alfred Wegener Institute, Helmholtz Center for Polar and Marine Research, Bremerhaven, PANGAEA, https://doi.org/10.1594/ PANGAEA.793020. 